Check for updates

Cite this: RSC Adv., 2022, 12, 681

\title{
Photoinduced and ground state conversions in a cyclic $\beta$-thioxoketone $\uparrow$
}

\author{
Mariusz Pietrzak, (D) *a Joanna Buczyńska, (D) a Fritz Duus, ${ }^{\mathrm{b}}$ Jacek Waluk (D) ac \\ and Poul Erik Hansen (DD ${ }^{b}$
}

The photochemistry of a cyclic $\beta$-thioxoketone (2-methyl-1-(2-thioxycyclohexyl)propan-1-one (MTPO)) is investigated by NMR, UV, and IR experiments supported by DFT calculations. MTPO exists as a tautomeric mixture of an enol and a thiol form. Irradiation at low temperature led to a cis-trans isomerization of the thiol form resulting in a rather unusual enethiol (3). This is followed by a transfer of the isopropyl methine proton onto the carbonyl carbon resulting in yet another enethiol isomer (4). The photoconversion mechanisms without water present are discussed. Photochemical experiments at ambient temperature showed involvement of water in the excited state and resulted in another ketoform (5). The same species was also obtained when the products of the low temperature experiments were kept in the dark at ambient temperature.

Received 13th December 2021 Accepted 16th December 2021

DOI: $10.1039 / \mathrm{d} 1 \mathrm{ra0} 020 \mathrm{~h}$

rsc.li/rsc-advances

formation of the -SH exorotamer of the (Z)-enethiol tautomer,

\section{Introduction}

$\beta$-Thioxoketones exhibit interesting structural features that attract unremitting attention of numerous research groups. This class of compound can exist as different tautomers including thiol and thione and can form different intramolecular hydrogen bonds. $\beta$-Thioxoketones have good chelating properties that are widely used in the organic synthesis ${ }^{1-3}$ and in the development of new drugs. ${ }^{4}$ They exhibit photochromic properties and are good models for investigation of photochemical phenomena such as excited-state intramolecular proton transfer (ESIPT), both experimentally ${ }^{5}$ and theoretically. ${ }^{6,7}$ The photochemistry revealed in the present paper leads to new unusual compounds and may shed more light on the photoreactions in $\beta$-thioxoketones, not least on the influence of the environment on these particular photoprocesses.

$\beta$-Thioxoketones show strong hydrogen bonding, tautomerism and upon irradiation in a matrix an unusual open form was observed $^{8-10}$ (Scheme 1), whereas in the liquid state a cistrans isomerization was found. ${ }^{11}$ The photoreaction mechanism is quite complex and has not yet been fully elucidated. Investigations of monothiodibenzoylmethane, carried out in various environments at different temperature ${ }^{11}$ demonstrated a stepwise mechanism. It was possible to distinguish between the

${ }^{a}$ Institute of Physical Chemistry, Polish Academy of Sciences, Kasprzaka 44, 01-224 Warsaw, Poland. E-mail: mpietrzak@ichf.edu.pl

${ }^{b}$ Department of Science and Environment, Roskilde University, Denmark

'Faculty of Mathematics and Science, Cardinal Stefan Wyszyński University, Dewajtis 5, 01-815 Warsaw, Poland

$\dagger$ Electronic supplementary information (ESI) available. See DOI: 10.1039/d1ra09020h observed in rigid matrices at low temperatures, and the subsequent rotational isomerization, occurring in a liquid state. The photoconversion yield was found to depend on the irradiation wavelength. Therefore, it was postulated that a specific electronic state - the second excited singlet state of $\pi \pi^{*}$ electronic origin - is responsible for efficient phototransformation. The proposed photochromic pathways involved both singlet and triplet routes.

In the present paper a cyclic derivative is investigated in the liquid state (Scheme 2). Our initial goal was to pinpoint an unusual open form by combining photoirradiation with simultaneous NMR detection of transient species. The experiments revealed a complex photochemistry, involving both reversible and irreversible reactions and two different photoproducts, as well as a product formed in the dark. We report the structure of the products and discuss the photoconversion mechanisms.

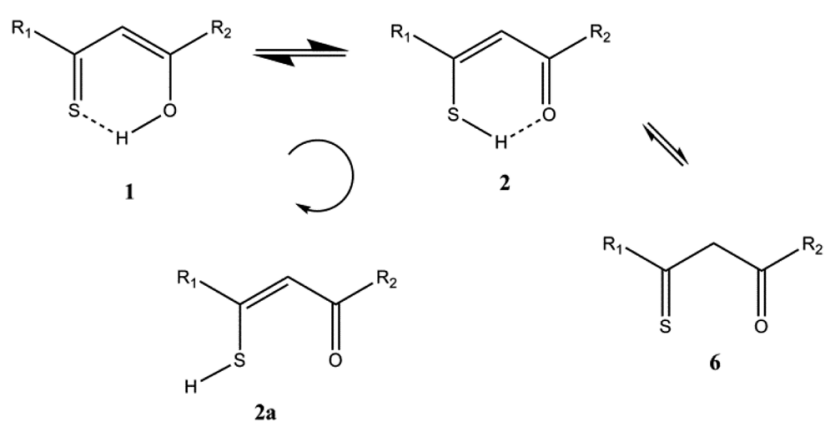

Scheme 1 Tautomeric and rotameric forms of $\beta$-thioxoketones. 


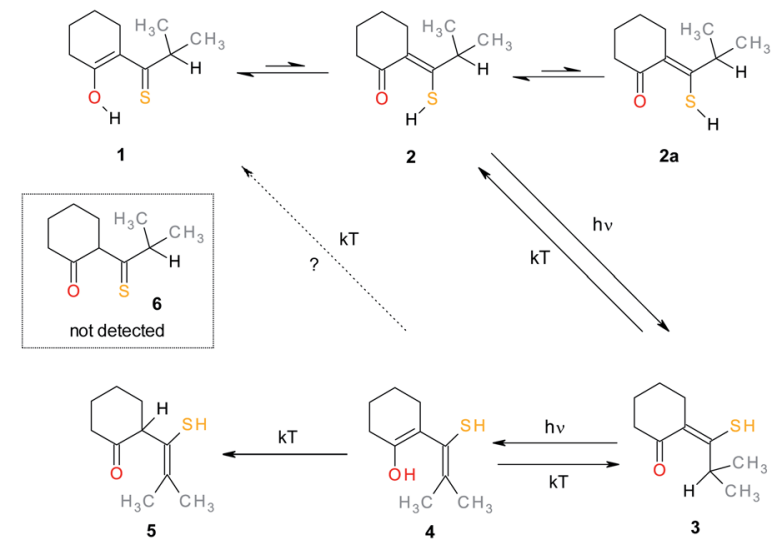

Scheme 2 Irradiation products of MTPO

\section{Experimental and computational details}

\section{Compounds and solvents}

MTPO was synthesized as described in ref. $16 . \mathrm{CH}_{2} \mathrm{Cl}_{2}, \mathrm{CD}_{2} \mathrm{Cl}_{2}$, or $\mathrm{CHCl}_{2} \mathrm{~F}$ were used as solvents. Deuterated $\mathrm{CD}_{2} \mathrm{Cl}_{2}$ in $0.75 \mathrm{ml}$ ampules was obtained from Cambridge Isotopes Laboratories Inc. (99.5\% D) or from Deutero GmbH (99.6\% D) and was used without further purification. Dichlorofluoromethane $\mathrm{CHCl}_{2} \mathrm{~F}$ with purity of $99 \%$ was obtained from Merck-Schuchardt and transferred into an NMR Young tube via a vacuum line. $\mathrm{CH}_{2} \mathrm{Cl}_{2}$ for spectroscopy (Uvasol) was purchased from Merck.

\section{Irradiation}

The irradiation was achieved using a UV-diode emitting at $365 \mathrm{~nm}$.

\section{UV-vis and IR spectroscopy}

The UV-vis spectra were recorded on a Shimadzu UV-3101PC spectrophotometer equipped with a home-built temperaturecontrolled sample chamber.

The IR spectra were obtained with an NICOLET MAGNA-IR 860 FTIR spectrometer, using a cell with $\mathrm{BaF}_{2}$ windows and $100 \mu \mathrm{m}$ path length. During these experiments, the same cell was used for alternative registration of IR and UV-vis spectra.

\section{NMR spectroscopy}

The recent developments in the field of NMR-UV methods are described in ref. 12. Here, the setup for combined NMR-UV laser experiments was used as described previously. ${ }^{11}$ Briefly, the base for it was a Bruker Avance II $300 \mathrm{MHz}$ NMR spectrometer with a WB magnet, equipped with a $5 \mathrm{~mm}$ BBI probe head for liquids, and an UV diode emitting light at $365 \mathrm{~nm}$. The light power reaching the sample was about $30-40 \mathrm{~mW}$ in the standard case when the quartz rod acting as a light pipe was immersed in the solvent and much less when the quartz rod was placed above the solvent meniscus (i.e., about $1 \mathrm{~cm}$ higher). Sample concentrations were in the range of 0.5-6 mM. Oxygen- free samples were prepared by bubbling the samples with dry nitrogen gas for at least 20 min inside NMR tubes, which were then mounted inside the NMR coil in an atmosphere of dry nitrogen. The temperature was checked with the use of a methanol thermometer. ${ }^{13}$ The NOESY (mixing time 0.7-1.5 s depending on $\mathrm{T}_{1}$ values), COSY, HSQC $(J=130 \mathrm{~Hz})$ and $\operatorname{HMBC}(J$ $=4 \mathrm{~Hz}$ ) experiments were performed with standard Bruker pulse programs (noesygpph, cosygpmfph, hsqcgpph, hmbcgpndqf). The reference for ${ }^{1} \mathrm{H}$ NMR at all temperatures was the signal of $\mathrm{CHDCl}_{2}$ set to $5.32 \mathrm{ppm}$.

\section{Calculations}

Initially, a conformational search was performed for 1-6, revealing several possible rotameric forms for each tautomer. This was done using density functional theory (DFT), with PBE functional and DZ basis set, as implemented in version 2019 of the Amsterdam Density Functional (ADF) package. ${ }^{14}$ Next, the geometry was optimized for one to three of the lowest energy rotameric forms of 1-6 (Scheme 3). This was initially done using ADF (B3LYP-D functional, DZP basis set). The obtained structures served as input for higher level calculations (B3LYP/6$311++\mathrm{G}(\mathrm{d}, \mathrm{p}))$, performed using Gaussian 16 software $^{15}$ Electronic transition energies and optimized $S_{1}$ geometries were obtained using time-dependent DFT. Geometries of the triplet states were optimized using unrestricted wave functions.

For each species in the ground electronic state, two sets of calculations were performed, first referring to isolated molecule, and the other simulating the presence of solvent, dichloromethane. The latter used the Polarizable Continuum Model implemented in Gaussian $16 .{ }^{15}$ Both sets gave very similar results. Because of that, excited state optimizations were done for molecules in vacuo.

The optimized structures served as input for calculations of both, IR and electronic absorption spectra.

\section{Results}

\section{Monitoring photoconversion by electronic spectroscopy}

Irradiation of 2-methyl-1-(2-thioxocyclohexyl)propan-1-one (MTPO also called 1 in the spectra) in $\mathrm{CH}_{2} \mathrm{Cl}_{2}$ or $\mathrm{CD}_{2} \mathrm{Cl}_{2}$ using a $30 \mathrm{~mW} 365 \mathrm{~nm}$ LED at $203 \mathrm{~K}$ (Fig. 1) leads to a complete bleaching of the absorption at $378 \mathrm{~nm}$. This is correlated with the rise of a band at $286 \mathrm{~nm}$. The substrate (MTPO) is not recovered during irradiation, or when the sample is left in the

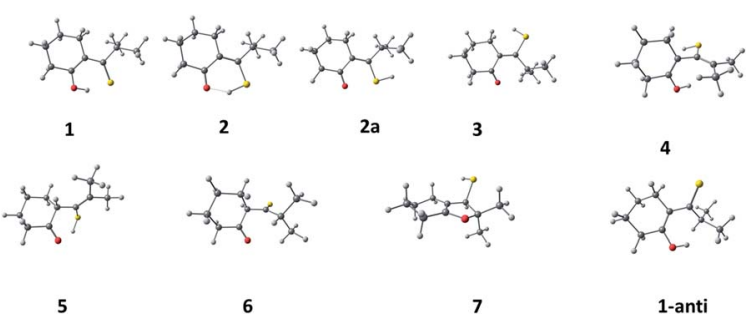

Scheme 3 Optimized lowest energy structures. 


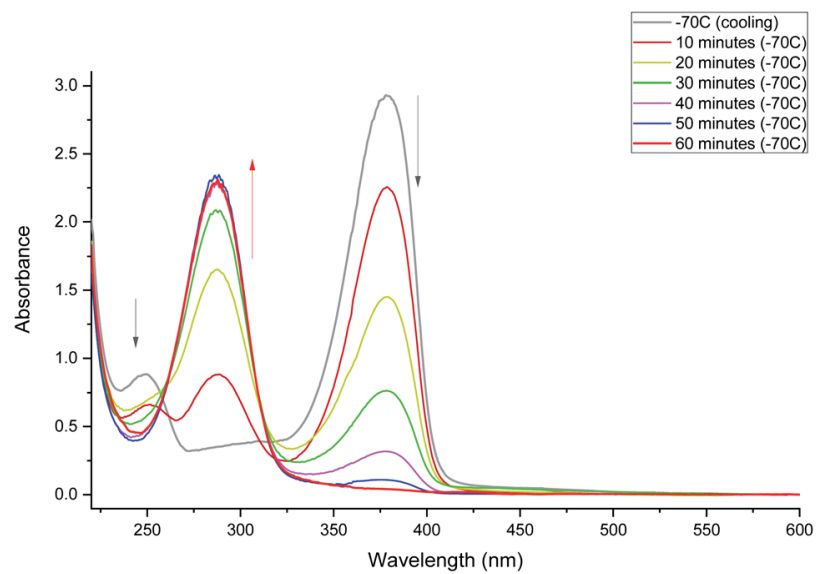

Fig. 1 Monitoring phototransformation at $203 \mathrm{~K}$. After 60 minutes of irradiation, complete disappearance of 1 was observed.

dark for about 1 hour. However, warming of the sample leads to a partial recovery of MTPO.

Irradiation at $293 \mathrm{~K}$ leads to a rapid decrease of the $376 \mathrm{~nm}$ band and increase of the $286 \mathrm{~nm}$ band. However, irradiation longer than 10 minutes does not lead to further depletion of the initial form. The absorbance at $376 \mathrm{~nm}$ starts to increase and, after reaching a certain value starts decreasing again (Fig. 2, top). This time, however, decrease of the $376 \mathrm{~nm}$ absorption is not accompanied by the increase at $286 \mathrm{~nm}$. Instead, a band appears at $268 \mathrm{~nm}$. Such behavior indicates a complex phototransformation scheme, involving more than just one photoproduct and a partial recovery of the substrate. As shown below, this is confirmed by NMR studies.

The above results show that at least two photoproducts, which we henceforth labelled $\mathbf{3}$ and $\mathbf{4}$, are formed upon irradiation. 3 and 4 are characterized by the absorption at 286 and $268 \mathrm{~nm}$, respectively.

After 10 minutes of irradiation at $293 \mathrm{~K}$, the absorbance of the main band at $376 \mathrm{~nm}$ fell to about $10 \%$ of its initial value. The photoproduct absorbs at $286 \mathrm{~nm}$ as mentioned above. The substrate can be recovered in the dark (Fig. 3). The recovery is bimodal: about $80 \%$ of the initial absorption is restored in about 1.5 hours, whereas full recovery takes more than 48 hours.

In order to enable reliable comparison with the NMR experiments, the absorption studies were carried out using the same concentration of MTPO, $c a \cdot 10^{-3} \mathrm{M}$ and in some cases even the same solution. This was possible, using cells of $1 \mathrm{~mm}$ path length, due to not very strong electronic absorption of MTPO: molar absorption coefficient of 10040 at $376 \mathrm{~nm}$ was determined for the $\mathrm{CH}_{2} \mathrm{Cl}_{2}$ solution at room temperature.

\section{Monitoring photoconversion by NMR}

Compound MTPO is known to exist as a tautomeric mixture with the thioketo-enol form (1) (Scheme 1) dominating at ambient temperature. ${ }^{16}$ Upon cooling the thioketo-enol form (Fig. 4) becomes more dominant and at a temperature
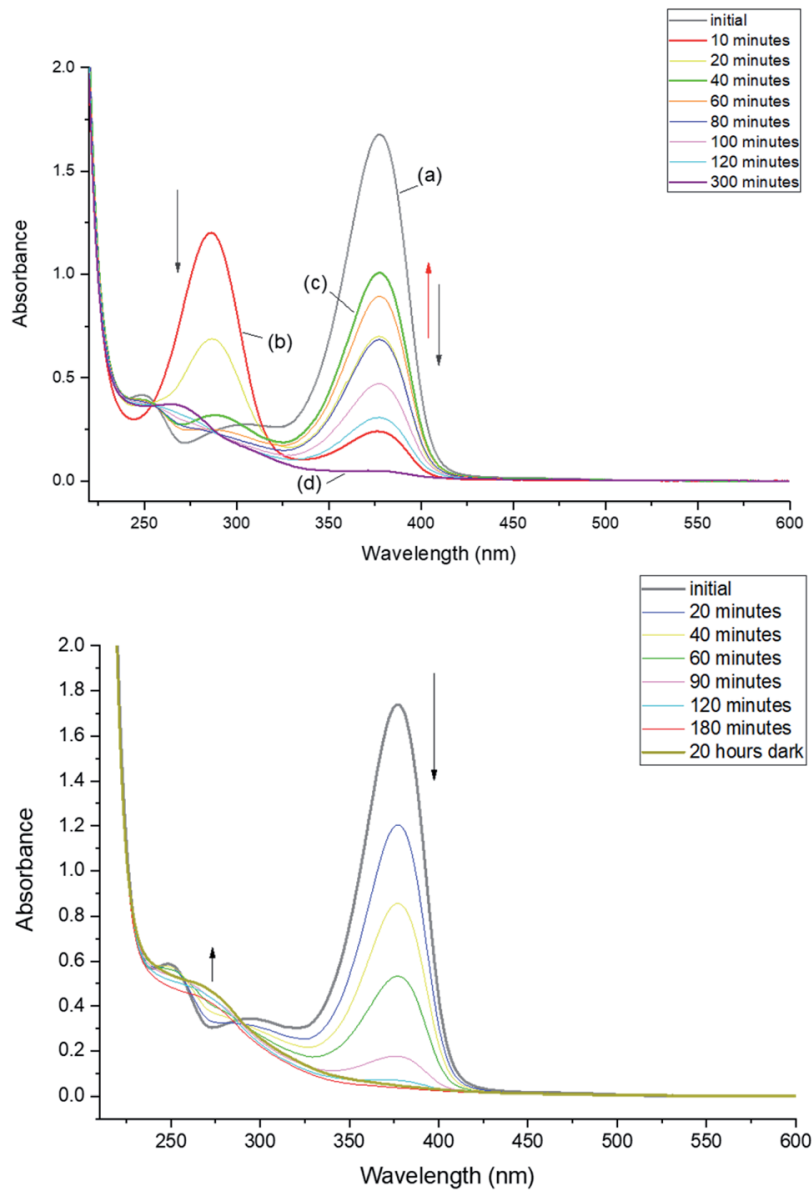

Fig. 2 Changes in absorption upon continuous irradiation at $293 \mathrm{~K}$. Top, $\mathrm{CH}_{2} \mathrm{Cl}_{2}$ solution. The initial absorption at $376 \mathrm{~nm}$ (a) strongly decreases after 10 minutes (b) and then starts increasing. After 40 minutes of irradiation (c), it starts decreasing again, reaching a very small value after 300 minutes (d). Bottom, $\mathrm{CD}_{2} \mathrm{Cl}_{2}$ solution. The main absorption peak constantly decreases and disappears after irradiation for 3 hours.

below $200 \mathrm{~K}$, the "OH" resonance (chelated proton) broadens.

It has been demonstrated that it is very important to keep the samples free of oxygen. ${ }^{8}$ Irradiation of a sample (30-40 $\mathrm{mW}$ at the sample) of MTPO (0.4-6.0 $\mathrm{mg}$ in $0.6 \mathrm{ml}$ of $\left.\mathrm{CD}_{2} \mathrm{Cl}_{2}\right)$ at $198 \mathrm{~K}$ led at first to product 3 (Fig. 5 and Scheme 2). At longer times also product 4 was formed and eventually all of 3 was converted to $\mathbf{4}$, which was stable in the dark at this temperature. However, if the sample containing $\mathbf{4}$ was warmed to room temperature it was partly transformed into the end product (5) and partly converted back to the starting material MTPO (Fig. 5d). The end ratio of 5/MTPO was 45/55 but it can be a function of the temperature during the warming up procedure, substrate concentration, water content, etc.

In a similar experiment, the solvent was $\mathrm{CHCl}_{2} \mathrm{~F}: \mathrm{CD}_{2} \mathrm{Cl}_{2}$ $10: 1$ mixture and the temperature $150 \mathrm{~K}$. After $10 \mathrm{~min}$ of irradiation 3 was formed. After 60 min of irradiation all was converted into 4. However, in this case the reaction mixture 


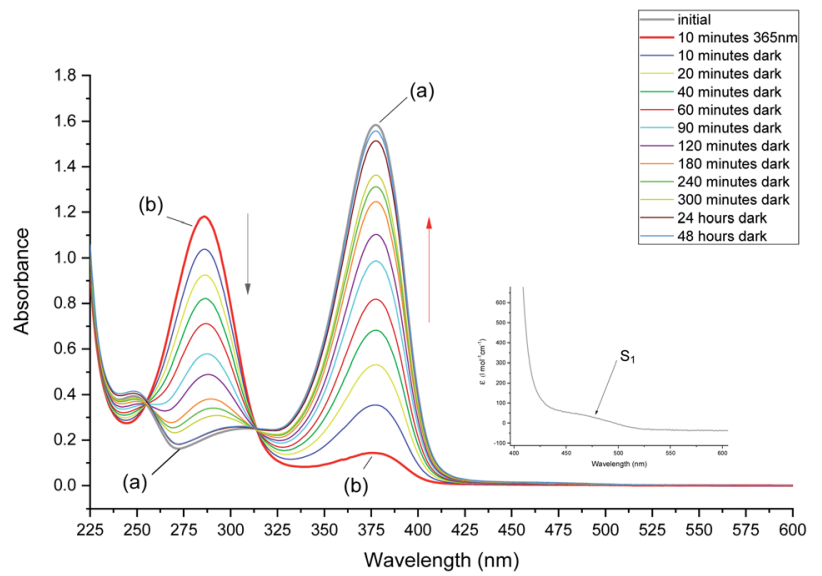

Fig. 3 Absorption changes recorded after irradiation of 1 in $\mathrm{CH}_{2} \mathrm{Cl}_{2}$ for 10 minutes at $293 \mathrm{~K}$. Initial absorption and the spectrum obtained after irradiation are labeled (a) and (b), respectively. The sample was then left in the dark, which led to the total recovery of the substrate after 48 hours. The inset shows the location of the $S_{0}-S_{1}$ transition of 1 , detected as a band about 200 times weaker than the maximum at $376 \mathrm{~nm}$.

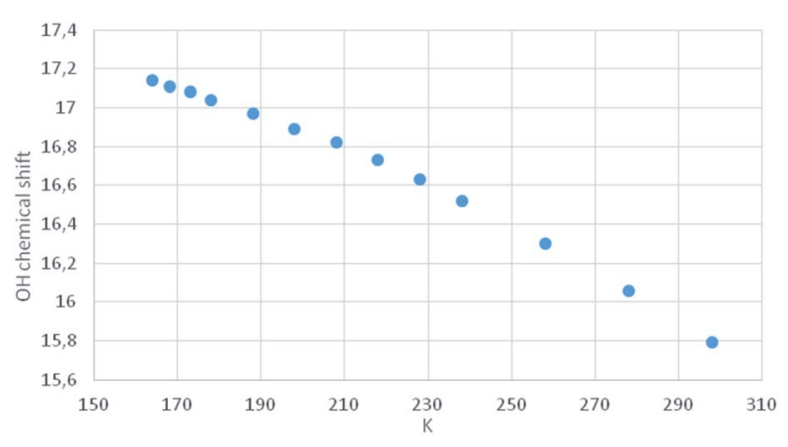

Fig. 4 Plot of "OH" chemical shift vs. temperature in $\mathrm{K}$ for 1.

was stored in a freezer at $253 \mathrm{~K}$ overnight, resulting in the partial formation of 3 (Fig. 6c). Then it was stored in a fridge at $277 \mathrm{~K}$ for four days, which led to full conversion into MTPO (Fig. 6).

Further experiments done at room temperature were performed in two different ways: (i) with the solvent as dry as possible, (ii) with the solvent containing relatively large amounts of water. In the first case $\mathbf{3}$ and $\mathbf{4}$ are formed. However, longer irradiation leads to the back conversion to MTPO and the formation of a small amount of 5 (Fig. 7). In the case of ii, MTPO is transformed to $\mathbf{5}$. A small amount of $\mathbf{4}$ is seen temporarily (Fig. 8). 5 was stable in the dark for days.

\section{Dark reactions}

Further experiments were also done to elucidate the reactions in the dark. Fig. 9 shows the back reaction of 3 in the dark at $228 \mathrm{~K}$ leading to the conversion into MTPO in a few hours. Under these conditions concentration of $\mathbf{4}$ was not changing. The back reaction of 3 in the dark at $298 \mathrm{~K}$, illustrated in Fig. 10, results in the conversion into MTPO. In this experiment 4 was not

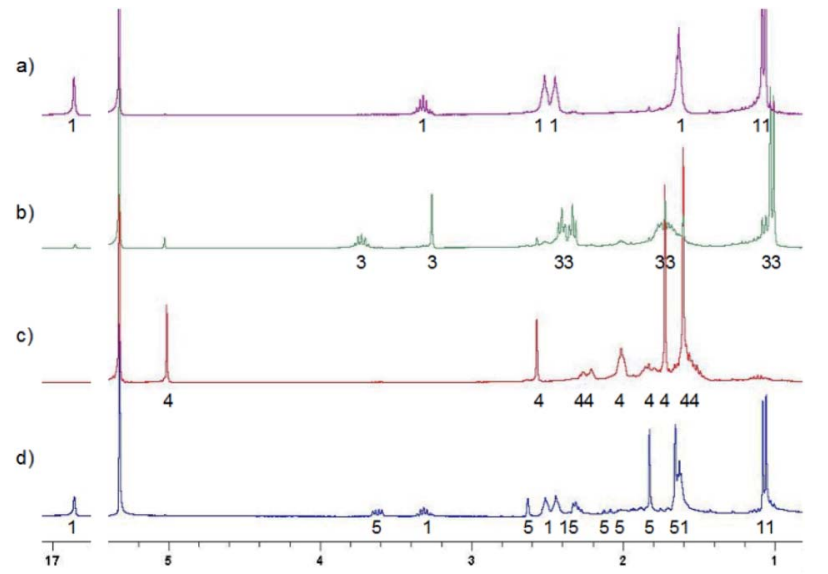

Fig. $5{ }^{1} \mathrm{H}$ NMR spectra of irradiation of MTPO in $\mathrm{CD}_{2} \mathrm{Cl}_{2}$ at $198 \mathrm{~K}$ with quartz rod inside the magnet placed above the sample's meniscus - (a) starting material $\left(6.0 \mathrm{mg}\right.$ in $\left.0.6 \mathrm{ml} \mathrm{CD} \mathrm{Cl}_{2}\right)$ at $198 \mathrm{~K}$; (b) after UV irradiation for 6 hours at 198 K; (c) after UV irradiation for 18 hours at 198 $\mathrm{K}$; (d) after standing in the dark at room temperature for 1 hour, measured at $198 \mathrm{~K}$. The numbers show the line assignment corresponding to the structures of Scheme 2.

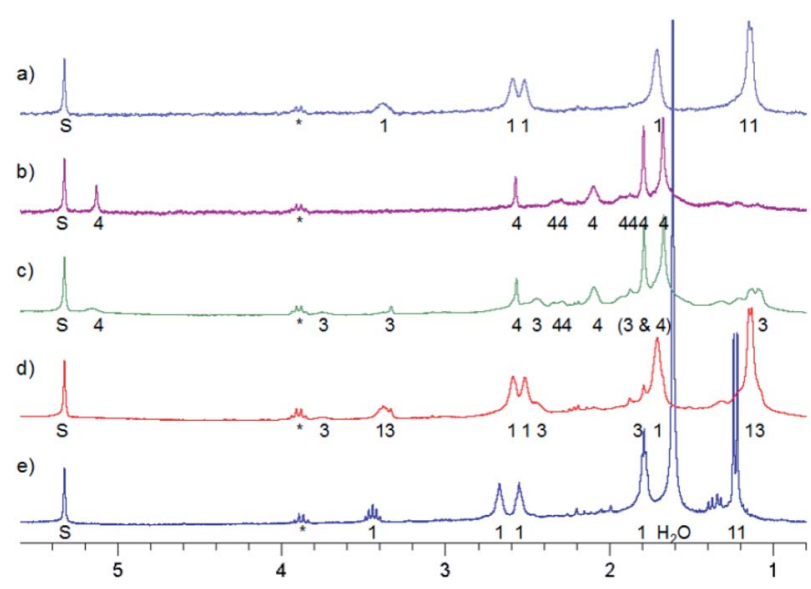

Fig. $6{ }^{1} \mathrm{H}$ NMR spectra of irradiation of MTPO $(0.9 \mathrm{mg}$ in $0.6 \mathrm{ml})$ in $\mathrm{CHCl}_{2} \mathrm{~F}: \mathrm{CD}_{2} \mathrm{Cl}_{2} 10: 1$ at $150 \mathrm{~K}$. (a) Starting material at $150 \mathrm{~K}$; (b) after irradiation for 1 hour at $150 \mathrm{~K}$; (c) kept in a freezer (253 K) over night, measured at $150 \mathrm{~K}$; (d) kept in a fridge $(277 \mathrm{~K})$ for eight hours, measured at $150 \mathrm{~K}$; (e) kept in a fridge (277 K) for four days, measured at $273 \mathrm{~K}$. The numbers show the line assignment corresponding to the structures of Scheme $2, \mathrm{~S}=$ solvent, $*$ = impurity.

observed and the possible influence of acid is eliminated by addition of basic $\mathrm{Al}_{2} \mathrm{O}_{3}$ to the sample. In both experiments no traces of $\mathbf{5}$ were detected.

\section{Monitoring photoconversion by IR}

The infrared spectrum of MTPO at ambient temperature is shown in Fig. 11 together with the calculated spectra. It clearly shows the presence of $\mathbf{1}$ and $\mathbf{2}$, but also that $\mathbf{2 a}$ is not present. The spectra after irradiation shows that $\mathbf{3}$ is growing and $\mathbf{1}$ is decreasing (Fig. 12). Very little happened prolonging the irradiation to $240 \mathrm{~min}$. 


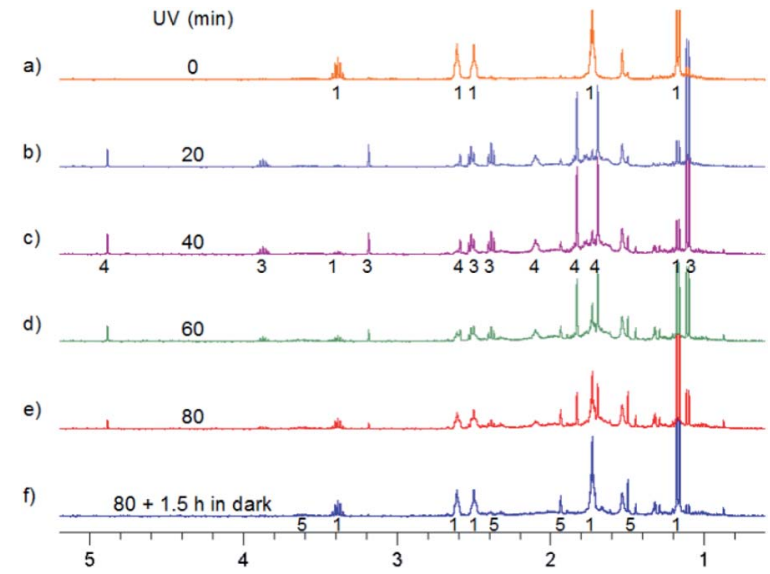

Fig. 7 Aliphatic part of ${ }^{1} \mathrm{H}$ NMR spectra of $0.7 \mathrm{mg} \mathrm{MTPO}$ in $\mathrm{CD}_{2} \mathrm{Cl}_{2}$ irradiated at ambient temperature outside the magnet. (a) Substrate; (b) -(e) after irradiation for certain periods: 20, 40, 60 and 80 min; (f) after 80 min irradiation and 1.5 hours in the dark. Sample without oxygen and with small amount of water (resonance at $1.55 \mathrm{ppm}$ is not intense). The numbers show the line assignment corresponding to the structures of Scheme 2 .

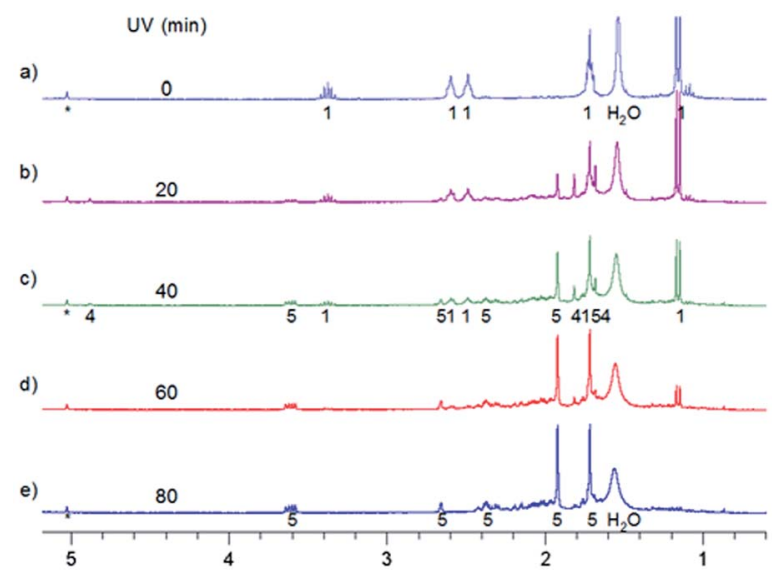

Fig. 8 Aliphatic part of ${ }^{1} \mathrm{H}$ NMR spectra of $0.4 \mathrm{mg} \mathrm{MTPO}$ in $\mathrm{CD}_{2} \mathrm{Cl}_{2}$ irradiated at $298 \mathrm{~K}$ with a quartz rod inside the magnet. (a) Substrate; (b)-(e) after irradiation for certain periods: 20, 40, 60 and $80 \mathrm{~min}$. Oxygen is eliminated by bubbling with $N_{2}$, but the amount of water is high (resonance at $1.55 \mathrm{ppm}$ is intense). The numbers show the line assignment corresponding to the structures of Scheme $2, *=$ solvent's satellite.

\section{Structures and assignments}

As both the intermediates, 3 and 4 are relatively stable at $198 \mathrm{~K}$ without irradiation, $1 \mathrm{D}$ and 2D NMR experiments were employed to identify these species.

Compound 3. As matrix isolation spectroscopy and NMR in solution led to different products (see, e.g., Fig. 5) (see Introduction), it is important to establish the structure of this cyclic derivative. The ${ }^{1} \mathrm{H}$ NMR spectrum shows the $\mathrm{CH}_{3}$ doublet at $1.02 \mathrm{ppm}(6 \mathrm{H})$ due to the isopropyl group. These are coupled to the methine proton at $3.73 \mathrm{ppm}(1 \mathrm{H})$. Two triplets integrating $2 \mathrm{H}$ each are observed at 2.33 and $2.39 \mathrm{ppm}$. In addition, there is one singlet at $3.26 \mathrm{ppm}(1 \mathrm{H})$ and a broad multiplet at $1.72 \mathrm{ppm}$

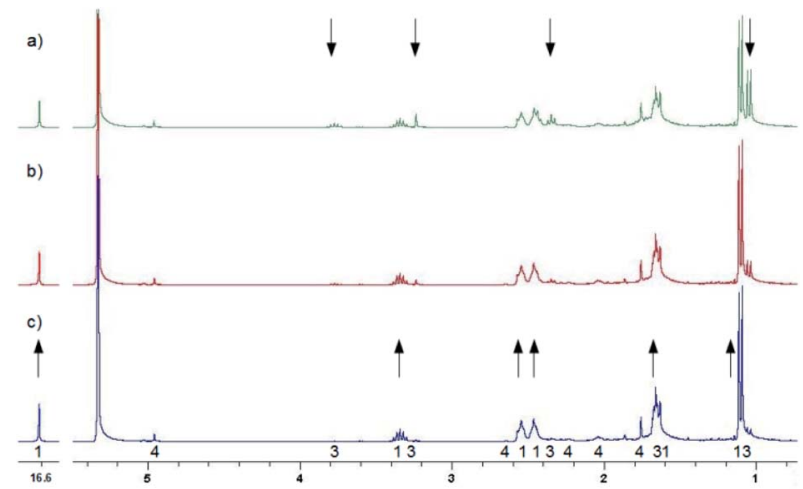

Fig. $9{ }^{1} \mathrm{H}$ NMR spectra of MTPO $\left(3.5 \mathrm{mg}\right.$ in $\left.0.6 \mathrm{ml} \mathrm{CD} \mathrm{Cl}_{2}\right)$ after irradiation at $198 \mathrm{~K}$ for 2 hours measured at $228 \mathrm{~K}$ in the dark. Assignments are shown by numbers. The arrows indicate the signals that change their intensity in time. (a) Just after irradiation and changing the temperature to $228 \mathrm{~K}$; (b) after $60 \mathrm{~min}$ in the dark; (c) after $120 \mathrm{~min}$ in the dark.

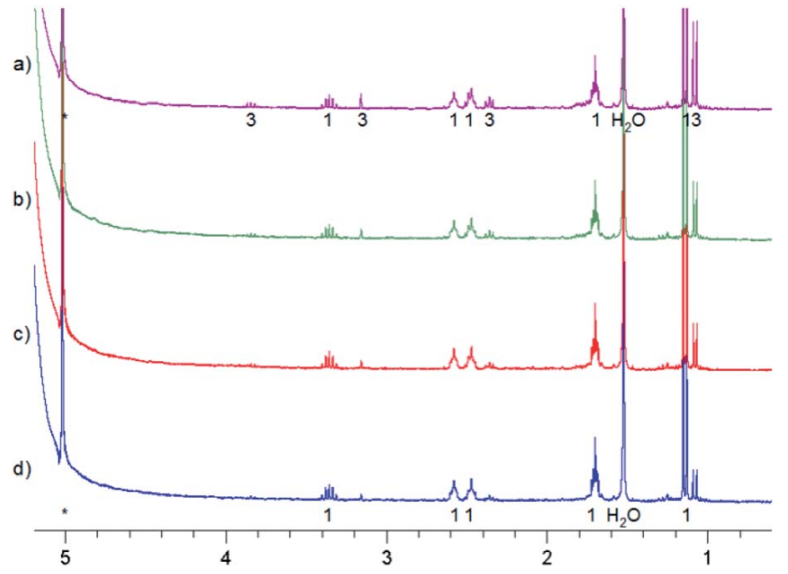

Fig. 10 Aliphatic part of ${ }^{1} \mathrm{H}$ NMR of $<1$ mg MTPO in $\mathrm{CH}_{2} \mathrm{Cl}_{2}$ deacidified with $\mathrm{Al}_{2} \mathrm{O}_{3}$. Sample irradiated for 2 min at ambient temperature outside the magnet. NMR spectrum recorded at $298 \mathrm{~K}$ without lock. The amount of water is high (resonance at $1.55 \mathrm{ppm}$ is intense). The numbers show the line assignment corresponding to the structures of Scheme 2, * = solvent's satellite. (a) Just after irradiation; (b) after $20 \mathrm{~min}$ in the dark; (c) after $40 \mathrm{~min}$ in the dark; (d) after $60 \mathrm{~min}$ in the dark.

$(4 \mathrm{H})$. The NOESY spectrum (ESI Fig. S3†) shows cross peaks between the $\mathrm{SH}$ proton at $3.26 \mathrm{ppm}$ and one of proton at $2.39 \mathrm{ppm}$ (ring proton). Furthermore, the $\mathrm{SH}$ proton shows a cross peak to the methyl signal at $1.02 \mathrm{ppm}$. The structure is shown in Scheme 2. This structure is the lowest energy one among the rotamers of $\mathbf{3}$ and shows clearly that the $\mathrm{CH}$ methine proton is pointing towards the $\mathrm{C}=\mathrm{O}$ group, leading to the chemical shift of $3.73 \mathrm{ppm}$ for this proton. Please notice, some variations in chemical shifts between different spectra may occur due to differences in temperature, solvent and concentrations.

Compound 4. The ${ }^{1} \mathrm{H}$ NMR spectrum shows two methyl singlets at 1.61 and $1.73 \mathrm{ppm}$ integrating $3 \mathrm{H}$ each, a broad signal integrating $2 \mathrm{H}$ at $2.01 \mathrm{ppm}$, a broad signal at $2.24 \mathrm{ppm}$ as 


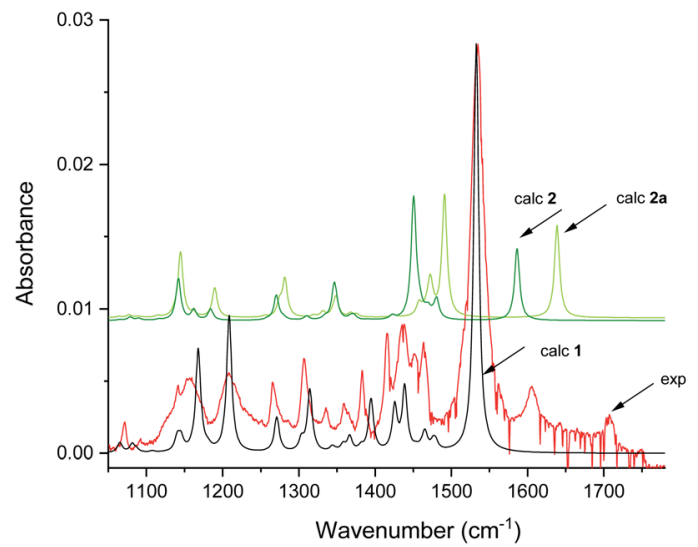

Fig. 11 Experimental spectra of the substrate and calculated IR spectra of 1 and 2 in $\mathrm{CD}_{2} \mathrm{Cl}_{2}$ at $298 \mathrm{~K}$. Scaling factor is 0.984 . Intensity scale is arbitrary (see Fig. S8 $\uparrow$ for comparison of simulated IR spectra of 1-6).

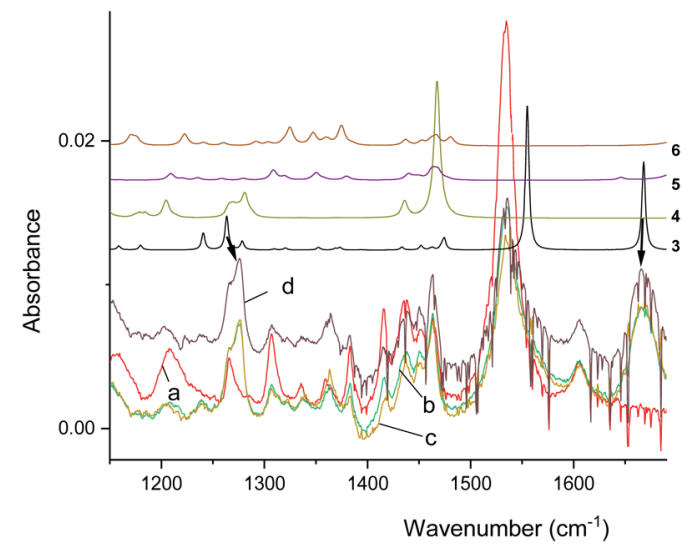

Fig. 12 Experimental IR spectra of the substrate (a) and the spectra obtained after irradiation for 5, 10, and 15 minutes $(b-d)$ in $\mathrm{CD}_{2} \mathrm{Cl}_{2}$ at $298 \mathrm{~K}$. The arrows indicate resonances due to 3 . Top, simulated spectra of 3-6 (arbitrary intensities, see Fig. S9† for comparison of relative intensities).

well as a sharp signals integrating $1 \mathrm{H}$ each at $2.57 \mathrm{ppm}$ and $5.01 \mathrm{ppm}$. In addition to these signals, broad resonances are observed around 1.83 and $1.57 \mathrm{ppm}$. The NOESY spectrum (ESI Fig. S4†) shows cross peaks from the SH proton at $2.57 \mathrm{ppm}$ to one of the ring protons $(2.24 \mathrm{ppm})$ and to one $\mathrm{CH}_{3}$ resonance at $1.73 \mathrm{ppm}$. The $\mathrm{OH}$ resonance at $5.01 \mathrm{ppm}$ shows a cross peak to the $\mathrm{CH}_{3}$ resonance at $1.57 \mathrm{ppm}$ and to one ring proton at $2.01 \mathrm{ppm}$. In addition, NOESY peaks are observed between the ring protons. The structure is shown in Scheme 2 and is confirmed by the correlation between calculated nuclear shieldings and observed chemical shifts (see below).

Compound 5. End product. The ${ }^{1} \mathrm{H}$ NMR spectrum shows two $\mathrm{CH}_{3}$ singlets at 1.66 and $1.83 \mathrm{ppm}$ integrating $3 \mathrm{H}$ each. Resonances integrating $1 \mathrm{H}$ each are seen at $2.63 \mathrm{ppm}(\mathrm{s})$ and $3.62 \mathrm{ppm}(1 \mathrm{H}, \mathrm{dd})$. In addition, a signal is found at $2.33 \mathrm{ppm}$ $(2 \mathrm{H})$ and some multiplets in the region from 1.6 to $2.2 \mathrm{ppm}$. The NOESY spectrum (ESI Fig. S5 $\dagger$ ) shows cross peaks from the SH proton at $2.63 \mathrm{ppm}$ to the ring protons $(2.2 \mathrm{ppm})$ and to one $\mathrm{CH}_{3}$ resonance at $1.83 \mathrm{ppm}$. The $\mathrm{CH}$ resonance at $3.62 \mathrm{ppm}$ shows a cross peak to one $\mathrm{CH}_{3}$ resonance at $1.66 \mathrm{ppm}$ and to two different ring protons at 2.33 and around $1.8 \mathrm{ppm}$. The structure is shown in Scheme 2. The COSY, HSQC and HMBC spectra (ESI Fig. S6-S8†), especially a carbonyl signal at $184 \mathrm{ppm}$ as well as two lines of $\mathrm{sp}^{2}$ carbons at 134 and $120 \mathrm{ppm}$ confirm the proposed structure.

Structures and NMR nuclear shieldings were initially calculated using the B3LYP functional and the Pople G(d) basis set. Nuclear shieldings were calculated using the GIAO method. ${ }^{17}$ The calculations showed that the structure for $\mathbf{4}$ has the $\mathrm{OH}$ group pointing towards the methyl groups. The nuclear shieldings were correlated to ${ }^{1} \mathrm{H}$ chemical shifts as seen in the ESI Fig. S1. $\uparrow$ The following correlation was established: $\delta_{\exp }=$ $1.0646 \times \sigma_{\text {calc }}+34.091, R^{2}=0.9772$.

\section{Calculations of ground and excited state structures and barriers}

In order to check the structural assignments and to elucidate photo- and dark conversion mechanisms, we carried out ground and excited states geometry optimizations of the initial keto (1) and enethiol (2) and (2a) forms, two postulated photoproduct structures (3 and $\mathbf{4}$ ), and the end product (5). Three other forms $(6,7$, and 1-anti) were also taken into account. Although not experimentally detected, they were considered as possible intermediates in the conversion processes. The structures are shown in Scheme 3. For each species, they correspond to the lowest energy rotamer, as revealed by a conformational search performed for each form. The exception is 2 , for which both chelated (2) and exo enethiol (2a) forms have been considered.

Optimization was followed by calculations of vibrational frequencies, electronic transition energies, and NMR patterns. All these procedures were then repeated including the presence of a solvent (dichloromethane). The results are shown in the ESI in Table S1. $\dagger$ The same ground state energy ordering is obtained for vacuum and solvent environment: $\mathbf{1}<\mathbf{2}<\mathbf{3}<\mathbf{5}<\mathbf{6}<\mathbf{7}<\mathbf{4}$. Thus, the photoproduct 4 is predicted to be thermodynamically least stable among the five observed species, which explains its decay in the dark (see, however, discussion on the origin of the barriers and their modifications by solvent impurities).

The simulated NMR spectra nicely agree with the experimental ones, confirming the assignments.

Calculations indicate that the strongest absorption band should be preceded by a much weaker band, significantly shifted to the red. This is readily observed for MTPO (see inset to Fig. 3).

\section{Discussion}

An aim of the present study is to shed more light on the photoconversion of $\beta$-thioxoketones, but also to possibly avoid a cistrans isomerization and furthermore to be able to observe the "open" form, 2 a.

By cooling down MTPO a line broadening of the "OH" resonance is observed below $200 \mathrm{~K}$. However, as seen from Fig. 4, no abrupt change in the "OH" chemical shift is seen. This is contrary to what was observed for the corresponding methyl 
derivative ${ }^{18}$ or for the open chain $\beta$-thioxoketones. ${ }^{19}$ In the latter case the jump in the chemical shift related to coalescence was attributed to freezing out of the open form (Scheme 1). Very little open form is apparently present in the case of MTPO. During irradiation, the formation of $2 \mathrm{a}$ can be monitored either by the XH chemical shift or by IR. The chemical shift of the XH proton depends on the species in equilibrium. If $2 \mathbf{a}$ is formed and being in equilibrium with 2 , the $\mathrm{XH}$ proton will be shifted to lower frequency until at a low temperature this species is "frozen" out and will be visible as separate resonances (for examples see thioacetylacetone and other derivatives). ${ }^{19}$ No such behavior is seen in the present case, so 2 a must be absent or formed in trace amounts only.

In the following, the discussion is divided between experiments done at low temperature and at ambient temperature. In the ambient temperature experiments it is important to distinguish between experiments with little or no water present or those with large amounts of water present.

The diagram of ground and excited singlet and triplet energy levels is presented in Fig. 13. It allows to understand the experimental findings related to photoconversion with small amounts of water present. Irradiation into the $S_{2}$ state of MTPO uses the wavelength, which is also absorbed by 2 and 3 (although in these cases, it involves the $S_{1}$ state, much weaker in absorption). Calculations clearly indicate the state responsible for the photogeneration of 3 : it is the triplet state of 2 . In fact, optimizations of the lowest triplet state in $\mathbf{2}, \mathbf{2 a}$, and 3 converge to the same structure, with the $\mathrm{SH}$ group located halfway between its ground state positions in these two forms. Thus, once the $T_{1}$ state of 2 is populated, it can decay into the ground state of either 2 or 3 .

The mechanism of $\mathbf{3} \rightarrow \mathbf{4}$ photoconversion seems to be different. It is now the lowest singlet excited state of 3 which adiabatically relaxes into $S_{1}$ of 4 . The ground state of 4 is thermodynamically least stable among 1-5. Therefore, conversion into the other forms is expected in the dark, exactly as observed.

Table 1 shows the calculated energy and free energy barriers for conversion between different forms in the ground electronic state. Of particular importance in the context of the conversion dynamics is the finding that the calculated barrier leading from

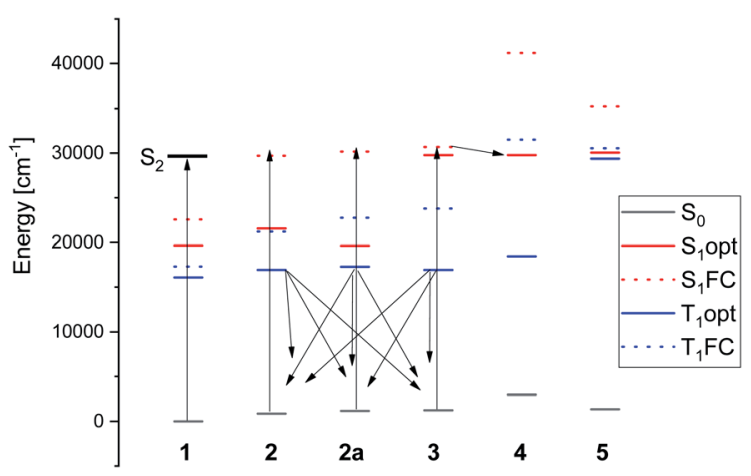

Fig. 13 Calculated energies of the ground and lowest $S_{1}$ and $T_{1}$ electronic states. Dashed bars indicate the energies calculated for ground state geometry.
Table 1 Calculated barriers for conversion between different ground state forms

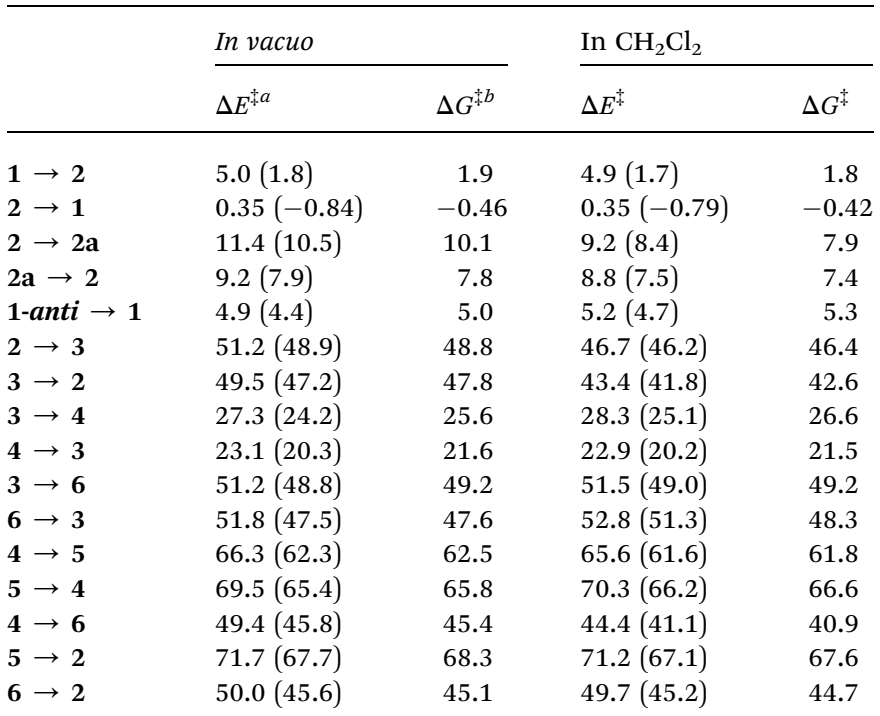

${ }^{a}$ Energy difference ( $\mathrm{kcal} \mathrm{mol}^{-1}$ ) at $0 \mathrm{~K}$ with respect to the starting form; ZPE-corrected values in parentheses. ${ }^{b}$ Free energy difference at 298.15 $\mathrm{K}$.

the first photoproduct back to the substrate $(3 \rightarrow 2)$ is much higher than that for $\mathbf{3} \rightarrow \mathbf{4}$ "uphill" transformation. Once $\mathbf{4}$ is formed, the barriers for its conversion into the other forms are quite high, and therefore these processes are expected to be slow. This is experimentally confirmed. Regarding the conversion of 3 into the substrate, calculations predict that it should be slow. This is indeed the case for the solution in $\mathrm{CH}_{2} \mathrm{Cl}_{2}$ (deacidified with basic $\mathrm{Al}_{2} \mathrm{O}_{3}$ ) (see Fig. 10).

The calculations thus suggest that photoconversion can produce three different species: 2a, 3, and 4 (Fig. 13). The former two are generated from the same precursor, the lowest triplet state of 2 , whereas 4 is formed from the lowest singlet excited state of $\mathbf{3}$. Because of relatively long lifetime, 3 and 4 can be seen by NMR, whereas $2 \mathbf{a}$ is difficult to detect due to low barrier for conversion into 2 , but it is not seen in the IR experiment (Fig. 11).

One can also understand why the $\mathbf{3} \rightarrow \mathbf{4}$ photoconversion is much faster than the $\mathbf{1} / \mathbf{2} \rightarrow \mathbf{3}$ phototransformation. The former occurs directly from the $S_{1}$ state of 3 ; calculations predict this process to be barrierless. On the other hand, excited state conversion of 1 into 3 involves several steps: photoexcitation of $\mathbf{1}$ is followed by intersystem crossing to the triplet state. Next, the direct precursor of $\mathbf{3}$, the triplet state of $\mathbf{2}$ has to be populated via the $\mathrm{OH} \rightarrow \mathrm{SH}$ hydrogen transfer. The calculations suggest that this process may be slightly uphill. NMR spectra of irradiated samples show that the photoconversion occurs in the order: MTPO $\rightarrow \mathbf{3} \rightarrow \mathbf{4}$.

An alternative channel to formation of 4 from 3 would be the methine proton abstraction from the triplet state of $\mathbf{3 .}^{\mathbf{2 0}}$ However, the calculations suggest that the yield of triplet formation in $\mathbf{3}$ may be low, due to barrierless conversion of $\mathbf{3}$ to 4 in the $S_{1}$ state. 
<smiles>CC(C)(C)/C(S)=C1\CCCCC1=O</smiles><smiles>CNC(C)(C)/C(SC)=C1\CCCCC1=O</smiles>

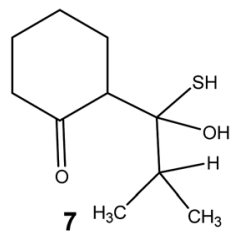

Scheme 4 Addition of water in the excited state.

4 is either going back to $\mathbf{1}$ or converting further to $\mathbf{5}$, depending on the temperature and solvent. The conversion to 1 is a thioenol to thioketone transformation and the reaction to the end product $\mathbf{5}$ is an enol to ketone transformation.

The influence of water can possibly be explained as seen in Scheme 4 . Water can add to the double bond in the excited state in an anti-Markovnikov fashion ${ }^{21}$ of either 2 or 3 leading to 7.7 can now dehydrate going back to 2,3 or go on to 5 . This is supported by the fact that $\mathbf{3}$ is not found when the irradiation of MTPO is conducted in the presence of large amount of water (Fig. 8).

Natural processes in the dark were observed at different temperatures, i.e.

- Below $198 \mathrm{~K} 3$ and 4 are stable (freon, Fig. 6 and $\mathrm{CD}_{2} \mathrm{Cl}_{2}$, Fig. S2†).

- At $228 \mathrm{~K} 3$ goes to MTPO, 4 is stable $\left(\mathrm{CD}_{2} \mathrm{Cl}_{2}\right.$, the amount of water is unknown, Fig. 9).

- At $253 \mathrm{~K}$ a small amount of 4 is converted to 3 (freon, high water contents, Fig. 6c).

- At $277 \mathrm{~K} 4$ goes to MTPO (freon, high water contents, Fig. 6d).

- At $298 \mathrm{~K} 4$ goes to 5 and MTPO $\left(\mathrm{CD}_{2} \mathrm{Cl}_{2}\right.$, the amount of water is unknown, Fig. $5 \mathrm{~d})$ and 3 goes mainly to $\mathbf{M T P O}\left(\mathrm{CD}_{2} \mathrm{Cl}_{2}\right.$, low water content, Fig. 7).

Based on these observations one can argue that the reaction pathway in the dark is the following:

$5 \leftarrow \mathbf{4} \rightarrow \mathbf{3} \rightarrow$ MTPO or alternatively $5 \leftarrow \mathbf{4} \rightarrow$ MTPO $\leftarrow 3$. The reactions $\mathbf{4} \rightarrow \mathbf{5}$ and $\mathbf{4} \rightarrow$ MTPO are competitive and depend on temperature and solvent because the 5/MTPO conversion rate varies substantially.

In summary, the overall picture of photoconversion of MTPO without water present involves rotamerization in the triplet state of 2 leading to either $2,2 \mathrm{a}$ or $\mathbf{3}$, and a much faster $\mathbf{3} \rightarrow \mathbf{4}$ phototransformation, a barrierless downhill process occurring after $\mathrm{S}_{1}$ excitation of 3 . It would be instructive to determine the time scales of these processes and to check for different possible routes leading to the doorway triplet state of 2 using ultrafast spectroscopy. In case of large amounts of water present a different route is taken as seen in Scheme 4. Even more challenging seems to be the elucidation of ground state kinetics. While the intramolecular conversion barriers seem to be high, the presence of water, traces of acid or other solvent impurities can drastically increase the reactivity.

\section{Conclusions}

Irradiation of MTPO (a cyclic $\beta$-thioketone) was studied by UV, IR and NMR. In the latter case both with irradiation outside the magnet and inside the magnet. The UV and NMR experiments were performed both at low temperature and at ambient temperature. Three new products were observed and identified, all of them enethiols. The structures were solved by 1D and 2D NMR experiment supported by DFT calculations. The photoconversion is clearly a way of creating new, unusual enethiols. One of them is stable at room temperature (5) and two others (3, 4) can be frozen at lower temperatures. The results of DFT calculations in the ground and excited states allow us to propose the pathway of photoreactions under study. The photoconversion process is discussed in dry solutions and in solutions containing more water. In both cases the initial step is conversion of MTPO into 3 via the $S_{2}$ state of MTPO. This is followed by a proton transfer in the excited state into the triplet state of 2. This is then transferred into 3. 4 is formed from the lowest excited singlet state of 3 . Reactions in the dark reveal that 4 can convert either to 5 or go back to MTPO, most probably through 3. In the water case, water is suggested as being part of the final conversion of $\mathbf{3}$ into $\mathbf{5}$. Such a complex picture can be even extended by further experiments conducted in the presence of oxygen.

\section{Conflicts of interest}

There are no conflicts to declare.

\section{Acknowledgements}

This work was partially supported by the European Union's Horizon 2020 research and innovation program under the Marie Skłodowska-Curie grant agreement No. 847413. Scientific work published as part of an international co-financed project founded from the program of the Ministry of Science and Higher Education entitled "PMW" in the years 2020-2024; agreement no. 5005/H2020-MSCA-COFUND/2019/2. JB and JW acknowledge the support from the Polish National Science Centre (NCN; grant no. 2017/26/M/ST4/00872), the PL-Grid infrastructure, and the Interdisciplinary Centre for Mathematical and Computational Modelling for a computing grant (grant no. G17-14).

\section{References}

$1 \mathrm{~K}$. S. Sharath Kumar, H. Ananda, S. Rangappa, S. C. Raghavan and K. S. Rangappa, Regioselective competitive synthesis of 3,5-bis(het) aryl pyrrole-2carboxylates/carbonitriles vs. $\beta$-enaminones from $\beta$ thioxoketones, Tetrahedron Lett., 2021, 82, 153373.

2 T. Murai, The Construction and Application of $\mathrm{C}=\mathrm{S}$ Bonds, Top. Curr. Chem., 2018, 376, 31.

3 I. S. Semenova, V. N. Yarovenko, K. S. Levchenko and M. M. Krayushkina, Synthesis of 1,3-thioxoketones from salicylaldehyde, Russ. Chem. Bull., 2013, 62, 1022-1025.

4 P. C. Andrews, V. L. Blair, R. L. Ferrero, P. C. Junk, L. Kedzierski and R. M. Peiris, Bismuth(III) $\beta$ thioxoketonates as antibiotics against Helicobacter pylori 
and as anti-leishmanial agents, Dalton Trans., 2014, 43, 1279-1291.

5 C. H. Wang, Z. Y. Liu, C. H. Huang, C. T. Chen, F. Yi. Meng, Y. C. Liao, Y. H. Liu, C. C. Chang, E. Y. Li and P. T. Chou, Chapter Open for the Excited-State Intramolecular Thiol Proton Transfer in the Room-Temperature Solution, J. Am. Chem. Soc., 2021, 143, 12715-12724.

6 K. Shayan and A. Nowroozi, DFT and TD-DFT study of the enol and thiol tautomers of 3-thioxopropanal in the ground and first singlet excited states, J. Theor. Comput. Chem., 2017, 16, 1750034.

7 I. Tatić and N. Došlić, On the Robustness of Low-frequency Laser Control Schemes for Proton Transfer in Thioacetylacetone, Croat. Chem. Acta, 2004, 77, 83-88.

8 A. Posokhov, A. Gorsky, J. Spanget-Larsen, F. Duus, P. E. Hansen and J. Waluk, The structure of the phototransformation product in monothiodibenzoylmethane, Chem. Phys. Lett., 2001, 350, 502-508.

9 A. Gorski, Y. Posokhov, B. K. V. Hansen, J. Spanget-Larsen, J. Jasny, F. Duus, P. E. Hansen and J. Waluk, Photochromism in $p$-methyl(thiobenzoyl)acetone and related $\beta$-thioxoketones, Chem. Phys., 2007, 338, 11-22.

10 A. Gorski, Y. Posokhov, B. K. V. Hansen, J. Spanget-Larsen, J. Jasny, F. Duus, P. E. Hansen and J. Waluk, Photochromism and polarizations spectroscopy of $\mathrm{p}$ methyl(thiobenzoyl)acetone, Chem. Phys., 2006, 328, 205215.

11 M. Pietrzak, J. Dobkowski, A. Gorski, S. Gawinkowski, M. Kijak, R. Luboradzki, P. E. Hansen and J. Waluk, Arresting consecutive steps of a photochromic reaction: Studies of $\beta$-thioxoketones combining laser photolysis with NMR detection, Phys. Chem. Chem. Phys., 2014, 16, 91289137.

12 P. Nitschke, N. Lokesh and R. M. Gschwind, Combination of illumination and high resolution NMR spectroscopy: Key features and practical aspects, photochemical applications, and new concepts, Prog. Nucl. Magn. Reson. Spectrosc., 2019, 114-115, 86-134.
13 D. S. Raiford, C. L. Fisk and E. D. Becker, Calibration of methanol and ethylene glycol nuclear magnetic resonance thermometers, Anal. Chem., 1979, 51, 2050-2051.

14 G. te Velde, F. M. Bickelhaupt, E. J. Baerends, C. Fonseca Guerra, S. J. A. van Gisbergen, J. G. Snijders and T. Ziegler, Chemistry with ADF, J. Comput. Chem., 2001, 22, 931-967.

15 M. Frisch, G. Trucks, H. Schlegel, G. Scuseria, M. Robb, J. Cheeseman, G. Scalmani, V. Barone, G. Petersson and H. Nakatsuji, et al., Gaussian 16, Revision B.01, Gaussian, Inc., Wallingford CT, 2016.

16 F. Duus, $\beta$-Thioxo ketones. 2. Preparation and structure of some five- and six-membered 2-Acylcycloalkanethiones and 2-thioacylcycloalkanones, J. Org. Chem., 1977, 42, 3123-3127.

17 K. Wolinski, J. F. Hinton and P. Pulay, Efficient implementation of the gauge-independent atomic orbital method for NMR chemical shift calculations, J. Am. Chem. Soc., 1990, 112, 8251-8260.

18 U. Berg, J. Sandstrom, L. Carlsen and F. Duus, Betathioxoketones. Part 9. A dynamic ${ }^{1} \mathrm{H}$ nuclear magnetic resonance spectroscopic study of thioacetylacetone and related $\beta$-thioxoketones. Direct observation of the enol and the enethiol tautomeric constituents and their interconversion, J. Chem. Soc., Perkin Trans. 2, 1983, 13211325.

19 B. Andresen, F. Duus, S. Bolvig and P. E. Hansen, Variable temperature ${ }^{1} \mathrm{H}$ and ${ }^{13} \mathrm{C}$ NMR spectroscopic investigation of the enol-enethiol tautomerism of $\beta$-Thioxoketones. Isotope effects due to deuteron chelation, J. Mol. Struct., 2000, 552, 45-63.

20 Y. Ito, H. Nishimura, Y. Umehara, Y. Yamada, M. Tone and T. Matsuura, Intramolecular hydrogen abstraction from triplet states of 2,4,6-triisopropylbenzophenones: Importance of hindered rotation in excited states, J. Am. Chem. Soc., 1983, 105, 1590-1597.

21 Y. Chen, J. Zhang, Z. Tang and Y. Sun, Visible light catalyzed anti-Markovnikov hydration of styrene to 2-phenylethanol: From batch to continuous, J. Photochem. Photobiol., A, 2020, 392, 112340 . 